\title{
Comparative Behaviour of Multiphase Flowmeter Test Facilities
}

\author{
R. Vilagines ${ }^{1}$ and A.R.W. Hall ${ }^{2}$ \\ 1 Institut français du pétrole, IFP-Lyon, BP 3, 69390 Vernaison - France \\ 2 National Engineering Laboratory, East Kilbride - United Kingdom \\ e-mail: regis.vilagines@ifp.fr - ahall@nel.uk
}

Résumé - Comparaison des moyens d'essais de débitmètres polyphasiques — L'utilisation de débitmètres polyphasiques connaît un essor significatif depuis quelques années. La disponibilité de boucles d'essais de référence permettant de tester les débitmètres dans un domaine réaliste de débits et de pressions a contribué à faire accepter la débitmétrie polyphasique dans l'industrie. Des moyens d'essais de ce type existent au National Engineering Laboratories (NEL) au Royaume-Uni et à l'Institut français du pétrole (IFP) en France. Ils ont été utilisés dans le cadre de développements de débitmètres prototypes et pour l'évaluation de débitmètres commercialisés.

L'objectif de ce travail est d'examiner la performance d'un système simple composé d'un venturi et d'un gamma-densitomètre, testé successivement sur les boucles d'essais de l'IFP et du NEL, dans le but d'obtenir des éléments de comparaison des boucles d'essais polyphasiques entre elles.

Après une description des moyens d'essais, cet article présente une comparaison des résultats d'essais du venturi sur les deux installations.

\begin{abstract}
Comparative Behaviour of Multiphase Flowmeter Test Facilities - The application of multiphase flowmeters has started to grow significantly in recent years; one factor which has contributed to the acceptability of multiphase metering is the availability of multiphase test facilities where meters can be subjected to a realistic range of operating conditions. Such facilities are available at the National Engineering Laboratory (NEL) in the United Kingdom and at the Institut français du pétrole (IFP) in France and have been used both during development of multiphase flowmeters and for evaluation of commercially available multiphase flowmeters.
\end{abstract}

The objective of the current project was to examine the performance of a simple system consisting of a venturi meter and ${ }^{137}$ Cs gamma densitometer in both test facilities in order to gain some understanding of the comparative behaviour of the facilities. The measurement system was chosen to avoid any commercial bias in the testing and also to give direct access to the sensor responses which is valuable in interpreting the measurements.

The test facilities are described in the paper, together with a presentation of the results and conclusions of the venturi meter tests in the two facilities. 


\section{NOMENCLATURE}

$A_{\text {min }}$ venturi throat area

$C$ coefficient of discharge

$C$ ' multiplier to the discharge coefficient $C$ in multiphase conditions

$C_{m}$ added mass coefficient

$d$ venturi throat diameter

$D$ upstream internal diameter of venturi tube; upstream internal pipe diameter

$k \quad$ isentropic exponent of gas phase

$P \quad$ area averaged pressure

$u_{L} \quad$ mean velocity of liquid phase

$u_{P} \quad$ mean velocity of gas phase

$V_{t} \quad$ bubble rising velocity in still liquid

$\alpha$ gas fraction

$\beta$ venturi diameter ratio, $\beta=d / D$

$\varepsilon \quad$ expansibility [expansion] factor

$\rho$ density of the fluid

$\rho_{L} \quad$ density of the liquid phase

$\tau_{D} \quad$ drag force per unit volume

$\tau_{W}$ wall friction force per unit volume a bubble radius

$\rho_{p} \quad$ density of the bubbles $\mathrm{m}$

$\mathrm{m}^{2}$

dimensionless

dimensionless

dimensionless

$\mathrm{m}$

$\mathrm{m}$

dimensionless

$\mathrm{Pa}$

$\mathrm{m} / \mathrm{s}$

$\mathrm{m} / \mathrm{s}$

$\mathrm{m} / \mathrm{s}$

dimensionless

dimensionless

dimensionless

$\mathrm{kg} / \mathrm{m}^{3}$

$\mathrm{kg} / \mathrm{m}^{3}$

$\mathrm{kg} / \mathrm{m}^{3}$

$\mathrm{N} / \mathrm{m}^{3}$

$\mathrm{N} / \mathrm{m}^{3}$.

\section{Subscripts}

$x \quad$ projection on $x$ axis

\section{INTRODUCTION}

An important component of international standards work is the intercomparison of flow calibration facilities. This has been done for many years at single phase gas and liquid calibration centres by the use of a standard test piece, for example an orifice meter run, which is passed around the various laboratories for calibration. The results can then be compared statistically to check that the different national standards lie within the required tolerance.

The intercomparison of multiphase flow facilities presents extra challenges compared to single phase facilities because of various factors including: the number of individual measurements which constitute the reference measurements, the phase equilibrium and the unsteady flow behaviour of multiphase fluids. In single phase intercomparison, it is possible to make a test meter of better accuracy than the flow facilities, while in multiphase flow, the commercial meters which are available have an accuracy which is typically an order of magnitude worse than the reference facilities. In addition, an important point in any attempt at elaborating a systematic procedure to ensure that metering is consistent and unquestionable is to make use of a simple reference system which can be well understood without the "black box" difficulties which arise using a commercial instrument.

In this paper, a simple system consisting of a venturi meter and ${ }^{137} \mathrm{Cs}$ gamma densitometer is evaluated as a reference device for the intercomparison of multiphase flow facilities.

\section{EXPERIMENTAL FACILITIES}

\subsection{Test Equipment}

One of the most satisfactory measurement techniques in multiphase flows is the venturi meter which can be used over a wide range of conditions and give reproducible differential pressure signals. A series of venturi meters was tested at NEL during 1998 and 1999 and has provided a large background of information and experience [1,2]. The venturi geometry selected for the project is described on Figure 1a-1b.

The test equipment was designed with the following features:

- The venturi meter was installed horizontal, with no mixing or flow conditioning device upstream.

- The differential pressure measurement was made using a $142 \mathrm{~Hz}$, undamped differential pressure transmitter to catch the transient muliphase behaviour. Two interchangeable differential pressure transmitters with two calibrated ranges (0 to $1.5 \times 10^{5} \mathrm{~Pa}$ and 0 to $3.5 \times 10^{5} \mathrm{~Pa}$ ) were used to expand the workable envelope of the venturi system since such a wide range of differential pressures is observed across the whole operating flow domain of the testfacilities.

- A second differential pressure measurement was made between the upstream pressure tapping and a second tapping downstream of the venturi meter.

- Density was measured using a ${ }^{137} \mathrm{Cs}$ gamma densitometer mounted just upstream of the venturi meter.

\subsection{IFP Multiphase Flow-loop}

This facility was designed to reproduce multiphase flows as similar as possible to the industrial situations on production sites. The testing ground for the unit, as seen in Figure 3, and schematised in Figure 2, consists of a closed loop, equipped with a multiphase pump driven by a variable speed motor. There are two large capacity separators set up in series, downstream of the pump, in order to separate, accurately, the multiphase flow. The horizontal separator, V2, is a triphase separator, in order to make use of a liquid phase of two components. Domestic fuel oil, water, and nitrogen or methane are the usual test fluids in this facility. 


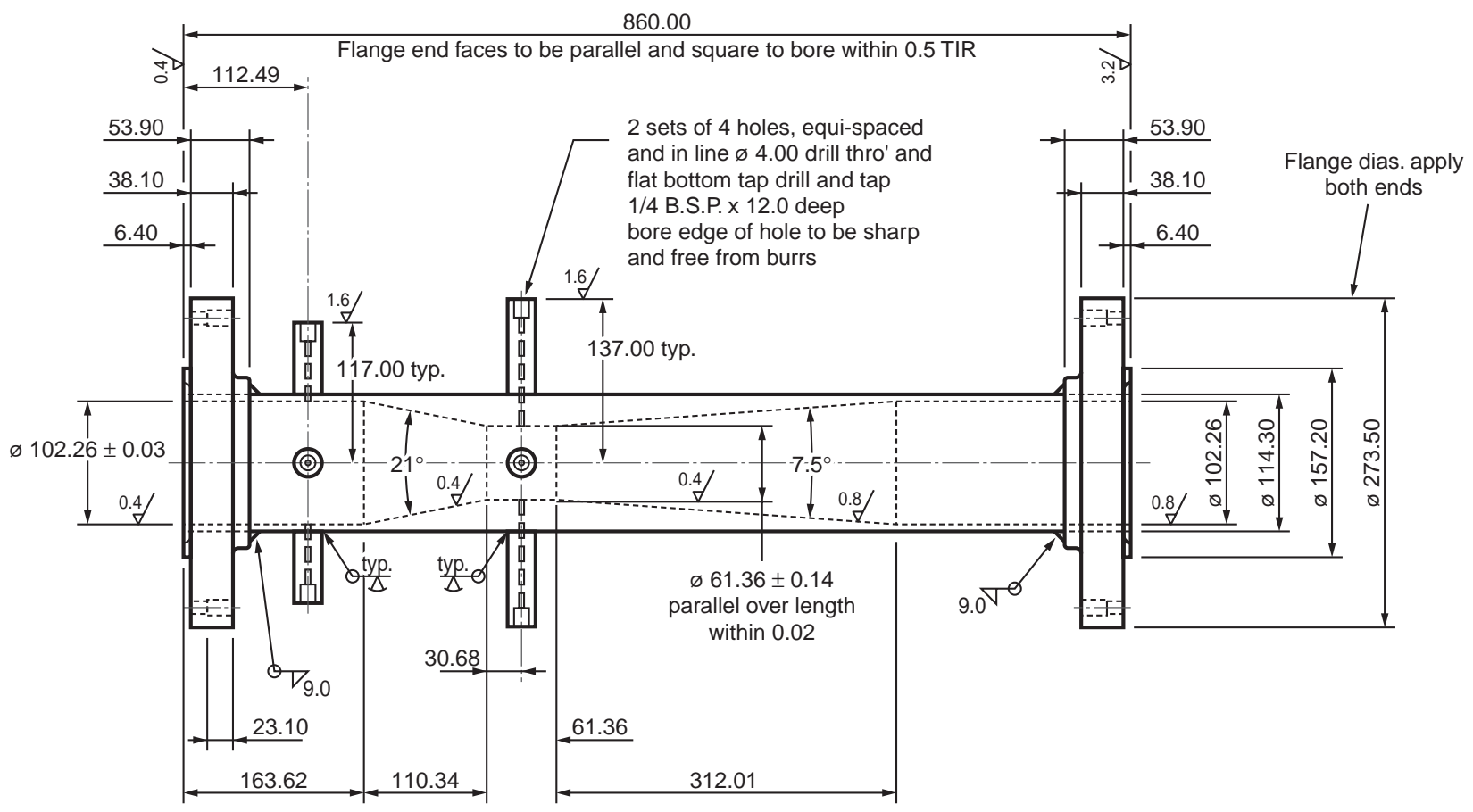

Figure 1a

Dimensions of the reference venturi meter.

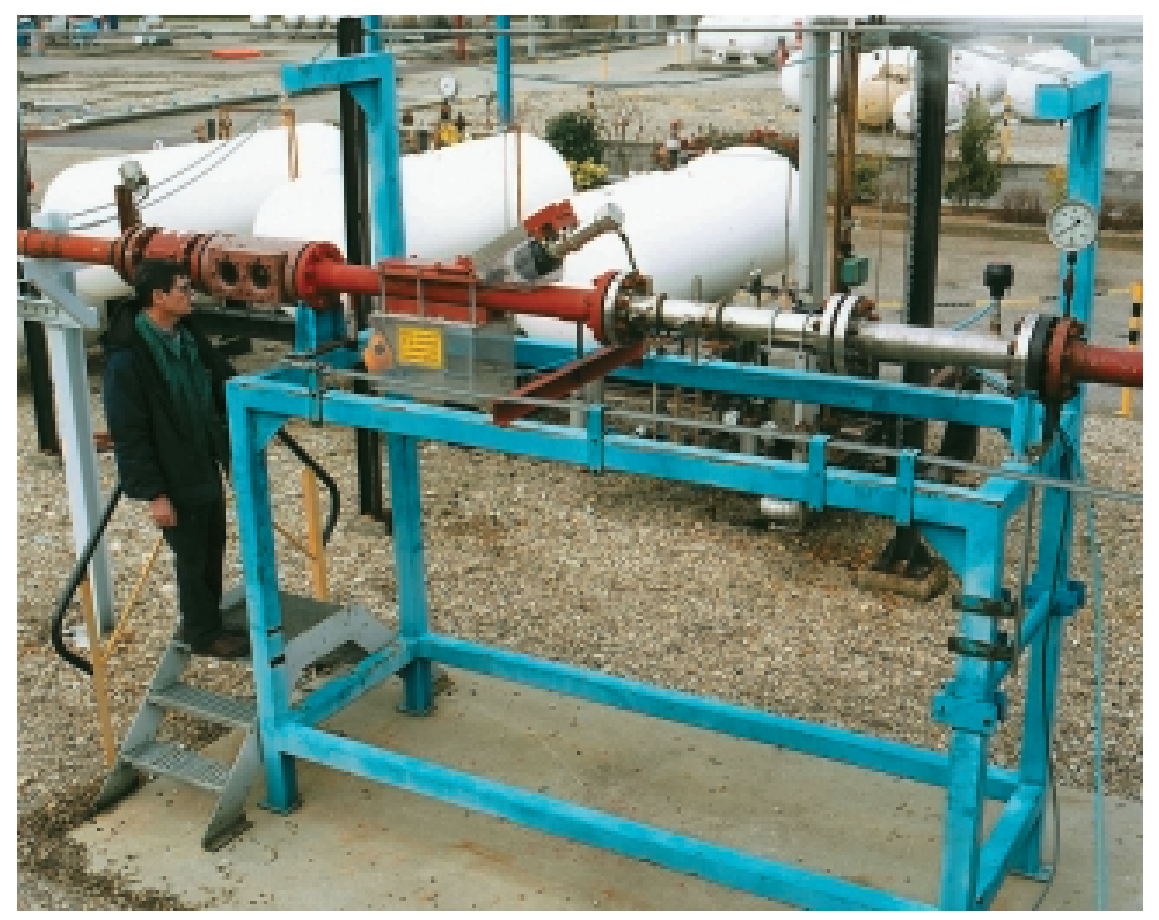

Figure $1 \mathrm{~b}$

View of the reference venturi meter spool piece with the gamma densitometer and the flow visualisation window. 


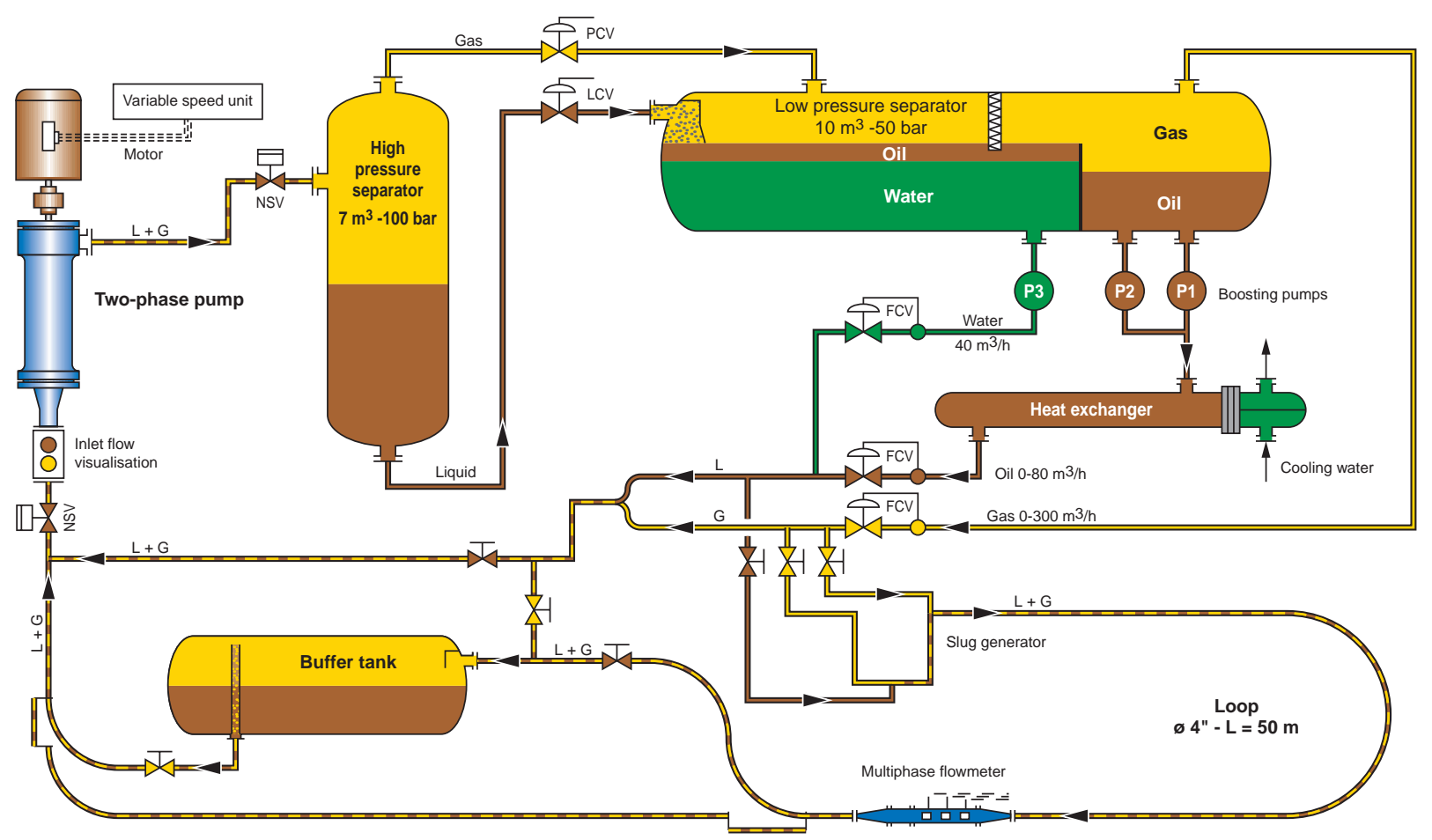

Figure 2

Layout of the IFP multiphase flow-loop.

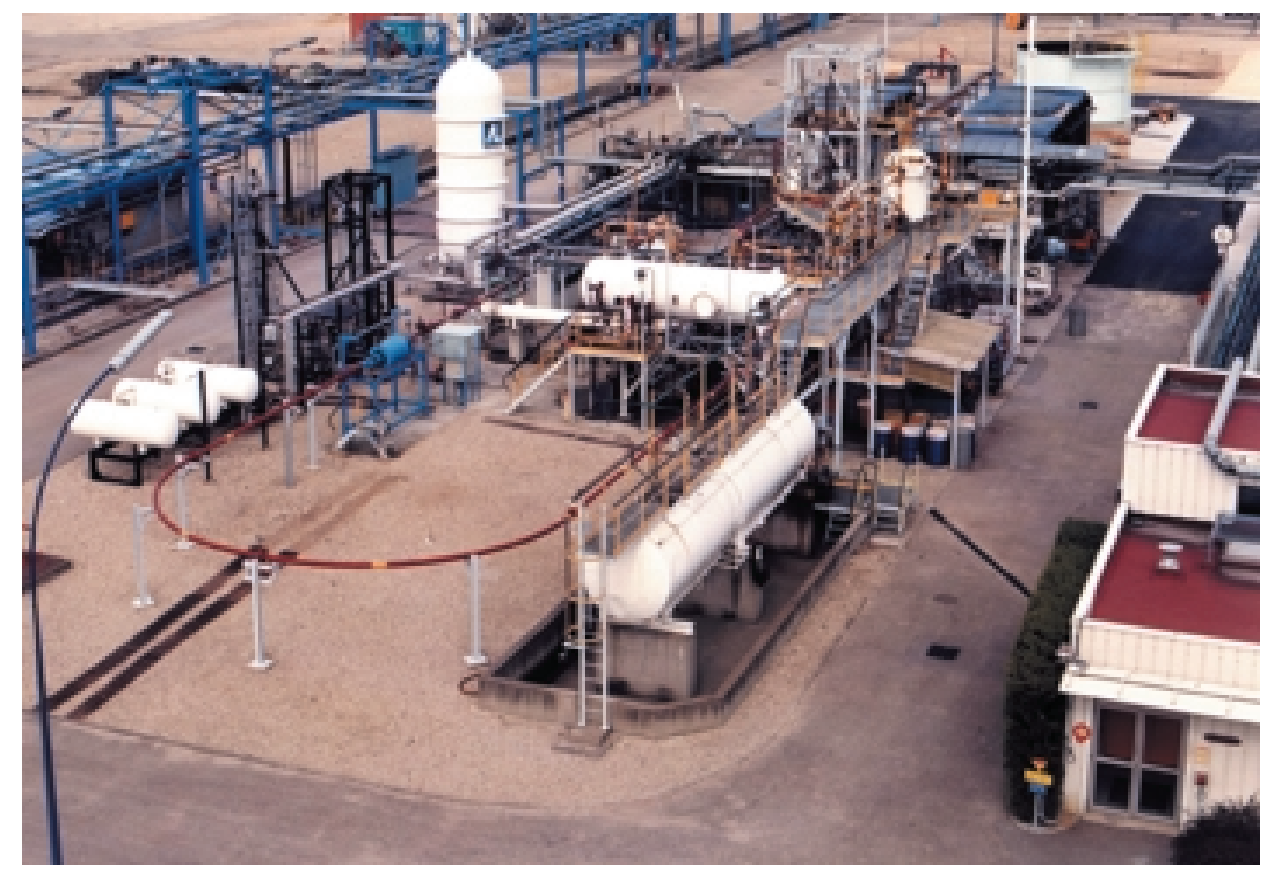

Figure 3

View of the IFP flow-loop showing a multiphase meter (in blue colour) during test. 
At the exit of the horizontal separator, three boosting pumps allow the liquid flow rates to be increased when necessary. The temperature of the oil phase can be controlled by means of a water heat exchanger.

The loop is equipped with a system of valves and forks leading the multiphase mixture towards different configurations of the loop corresponding to various functions. The test facility can be used with the short loop with a gas-liquid mixture at the multiphase pump intake, or, especially when testing a multiphase meter, with a $50 \mathrm{~m}$ long multiphase flow loop with a pipe internal diameter $D=0.1 \mathrm{~m}$. Additional equipment includes a pool for underwater testing, a "buffer tank" and a "slug generator". The "buffer tank" (IFP patent) can be used to absorb the fluctuations in the gas to liquid ratio at the inlet to a piece of equipment.

The facility can be operated within a range of static pressures from $3 \times 10^{5} \mathrm{~Pa}$ up to $5 \times 10^{6} \mathrm{~Pa}$. It permits the production of various multiphase flow regimes. The flow rates of the liquid and gas phase are independent of the static pressure chosen for testing since the flows are circulated in a closed loop. Total liquid flow rates from $1.38 \times 10^{-3} \mathrm{~m}^{3} / \mathrm{s}$ to $37.0 \times 10^{-3} \mathrm{~m}^{3} / \mathrm{s}$ and gas flow rates up to $98.0 \times 10^{-3} \mathrm{~m}^{3} / \mathrm{s}$ at line conditions can be measured.

\subsection{NEL Multiphase Flow-Facility}

The multiphase calibration facility at NEL is shown in Figure 5, and schematised in Figure 4. The test facility consists of a separator and a test section flow loop. The oil is supplied from the separator to the main oil pump and to the oil flow metering section. A side-stream sampling loop and a main bypass loop are fitted on the delivery side of the pump. The same configuration exists on the water side. The bypass loops permits control over the pressure and flow rate of the phases in the test section; the sampling loops provide information on the composition of the oil and water process streams. Heat exchanger circuits were in operation to stabilise the temperature of the working fluid, which was kept between 37 and $40^{\circ} \mathrm{C}$ during these tests.

After the oil and water have passed the reference metering section the oil and water are combined in the mixing section. The nitrogen, which is produced from a liquid nitrogen supply tank external to the building, is injected into the mixing section after passing through the gas flow reference metering section. The mixture is flowed into the test section which ran horizontally approximately $40 \mathrm{~m}$ to the venturi meter under test. The flow then returns to the separator where the oil and water are separated, and the gas exhausted to atmosphere.

\section{TEST DATA}

The data collected from the venturi meter during the tests consist of simultaneous recordings of line pressure, $\mathrm{Pa}$, fluid temperature, ${ }^{\circ} \mathrm{C}$, venturi meter differential pressure (upstream to throat), $\mathrm{Pa}$, venturi meter total pressure loss (upstream to downstream), $\mathrm{Pa}$, and fluid mixture density, $\mathrm{kg} / \mathrm{m}^{3}$. The measurements were recorded at a data collection frequency of $142 \mathrm{~Hz}$, for a period of $300 \mathrm{~s}$ once the flow conditions were stable.

The data collected from the reference facilities during the tests are the line pressure, $\mathrm{Pa}$, the fluid temperature, ${ }^{\circ} \mathrm{C}$, the liquid flow rates, $\mathrm{m}^{3} / \mathrm{s}$, and the gas flow rate, $\mathrm{m}^{3} / \mathrm{s}$.

The gas flow rate is calculated at the line pressure and fluid temperature and these are measured as close as practical to the upstream venturi tapping. Data were collected from the reference facility for the same $300 \mathrm{~s}$ period as from the venturi meter and calculated as an average value over this period, for each parameter listed.

The flow domains investigated on IFP and NEL test facilities are shown on Figure 6.

\section{EXPERIMENTAL DATA ANALYSIS}

The test data were analysed in two ways.

The first approach is to calculate the effective discharge coefficient of the venturi meter using the method outlined below, also discussed in [3] and [4].

In this approach, the formulation adopted in the international standard for measurement of fluid flow in closed conduits (IS0 5167-1 dated 1991) is adapted to multiphase flow conditions. The volumetric flow rate through a venturi meter is given by the following expression:

$$
Q=C A_{\min } \varepsilon C^{\prime} \sqrt{\frac{2 \Delta P}{\rho\left(1-\beta^{4}\right)}}
$$

In a multiphase flow, where the measurements of differential pressure and density both fluctuate, it is not satisfactory to use the ratio of $\Delta P / \rho$ in this expression. This may be avoided by calculating the mass flow rate:

$$
M=\rho Q
$$

from which it follows that:

$$
M=C A_{\min } \varepsilon C^{\prime} \sqrt{\frac{2 \rho \Delta P}{\left(1-\beta^{4}\right)}}
$$

In practice, the mass flow rate is an average value over the measurement period. Equation (3) becomes, by correct summation over the measurement period:

$$
\bar{M}=C A_{\min } \varepsilon C^{\prime} \sqrt{\frac{2}{\left(1-\beta^{4}\right)}} \times \overline{\sqrt{\rho \Delta P}}
$$

Therefore the correct quantity to calculate from the measured parameters of density, $\rho$, and differential pressure across the venturi, $\Delta P$, is the average of the square root of $\rho \Delta P$ evaluated for each individual measurement sample. 


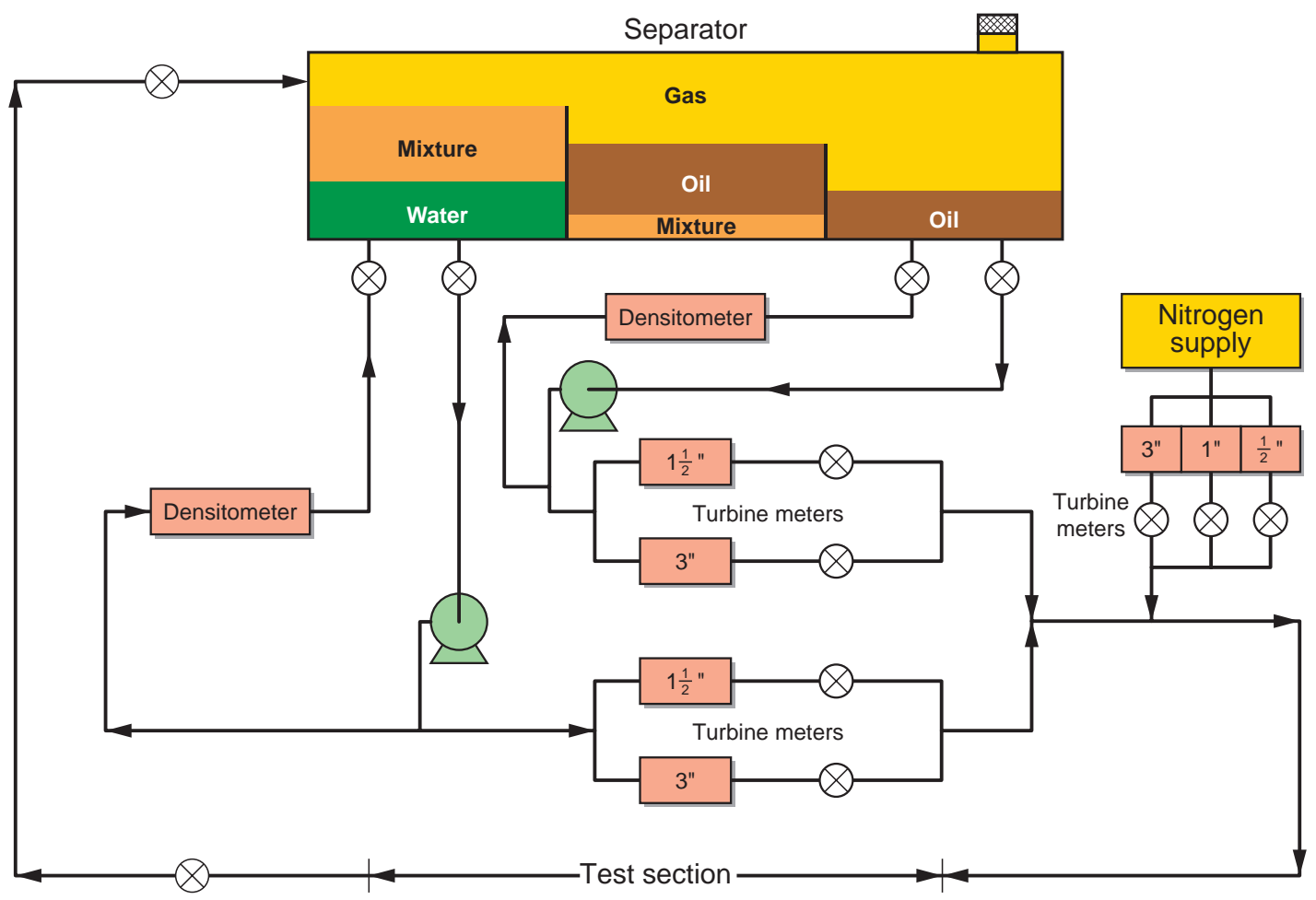

Figure 4

Layout of the NEL multiphase flow-loop.

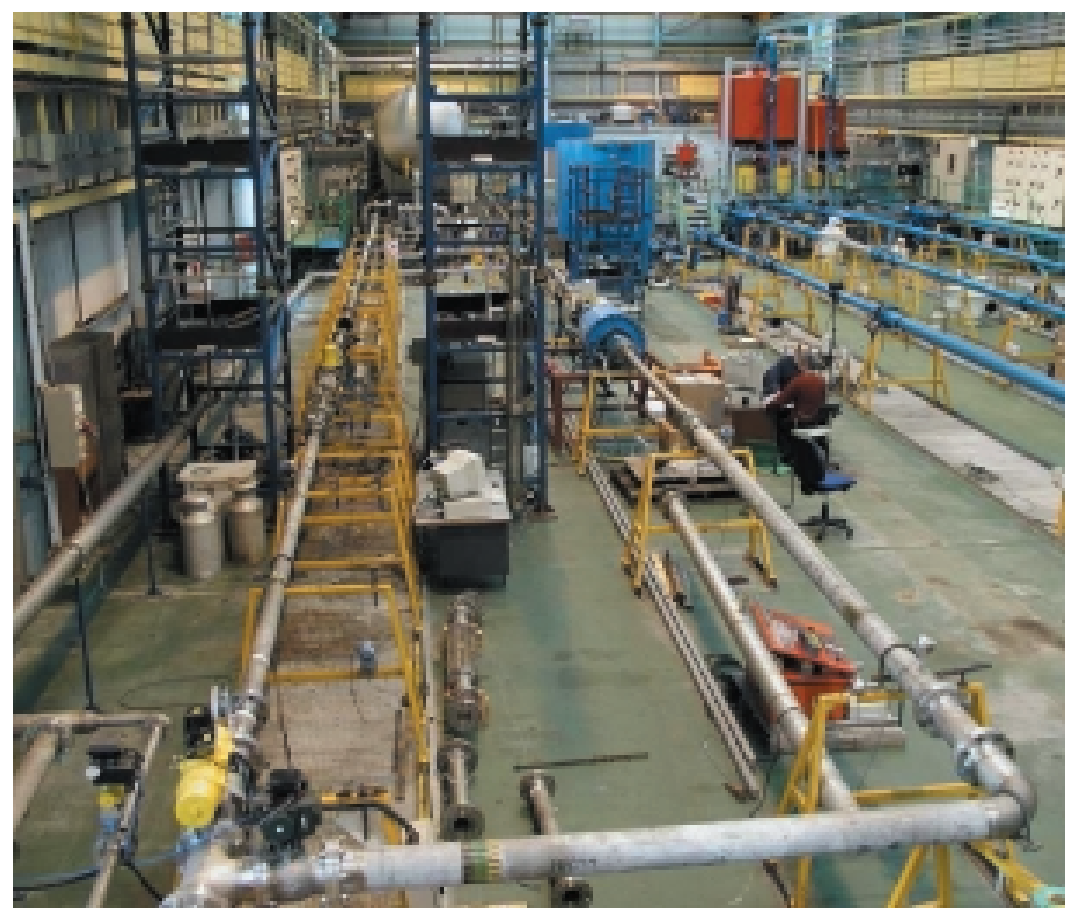

Figure 5

View of the NEL flow-loop showing a multiphase meter (in blue colour) during test. 


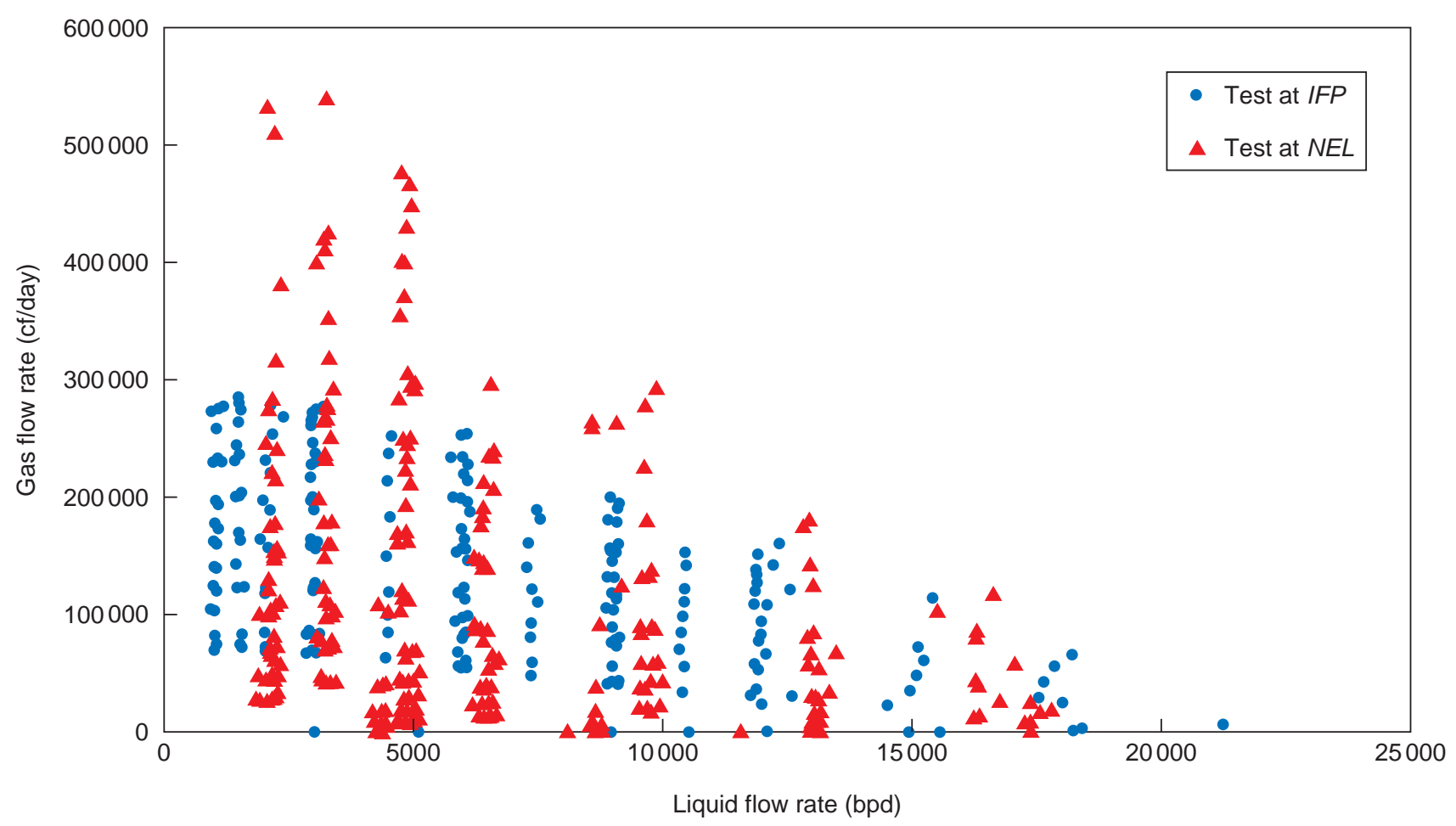

Figure 6

Experienced flow domain.

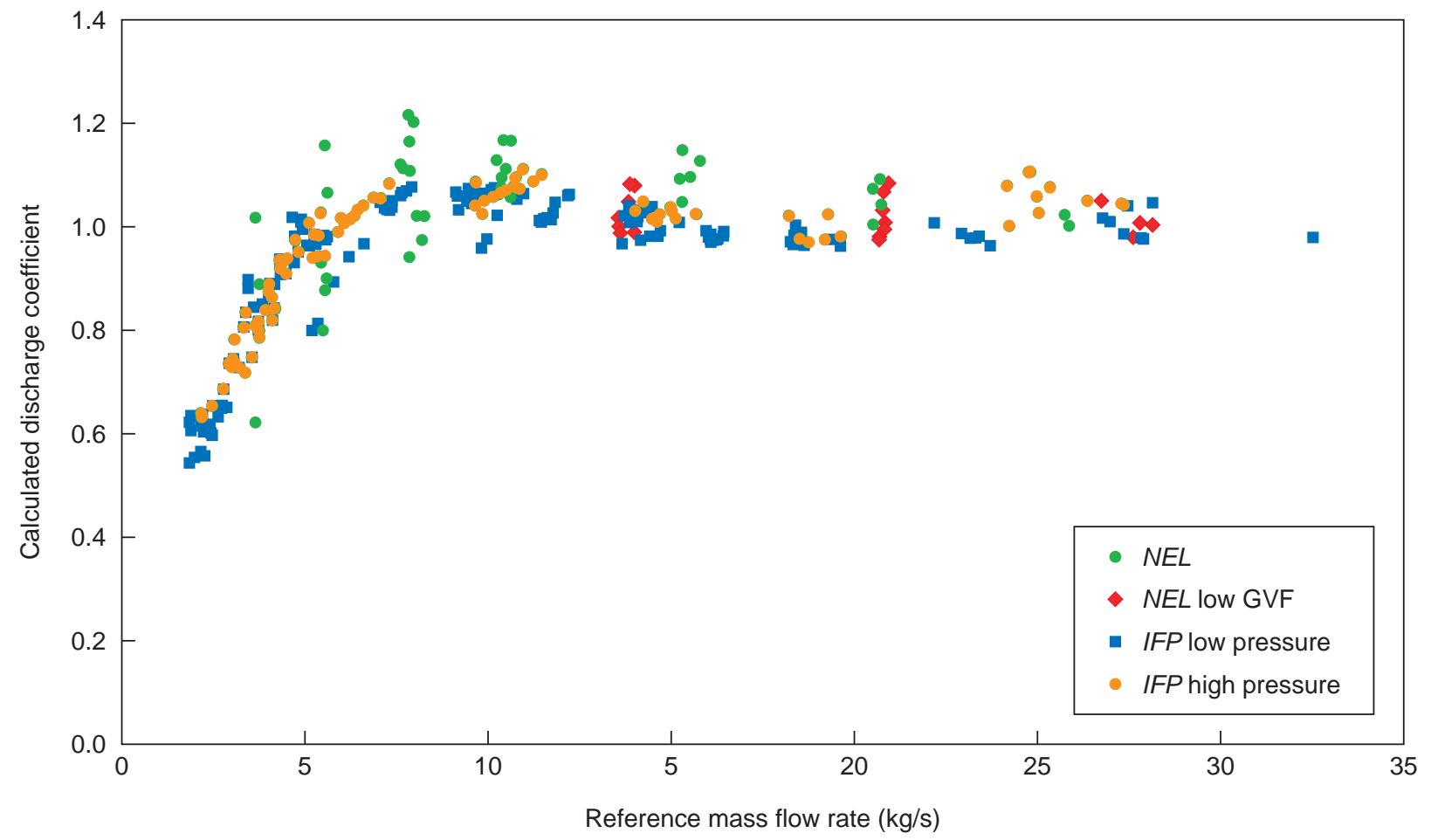

Figure 7

Computed venturi pressure discharge parameter $C^{\prime}$ versus total mass flow rate. 
In this situation we have reference volumetric flow rates for each of the individual streams of oil, water and gas and, knowing their densities at measured pressure and temperature, the reference total mass flow rate may be calculated from:

$$
M=\rho_{\text {oil }} Q_{\text {oil }}+\rho_{\text {water }} Q_{\text {water }}+\rho_{\text {gas }} Q_{\text {gas }}
$$

Having the average reference mass flow rate, $\bar{M}$, and the measured value of $\rho \Delta P$ from the venturi meter enables calculation of the discharge coefficient from:

$$
C^{\prime}=\frac{\bar{M}}{\varepsilon C A_{\min }} \sqrt{\frac{\left(1-\beta^{4}\right)}{2}} \times(\overline{\sqrt{\rho \Delta P}})^{-1}
$$

where $A_{\min }=\pi d^{2} / 4$ is the venturi throat area and $\beta$ is the ratio of throat diameter, $d$, to full pipe diameter, $D$, which will be specific to each venturi meter tested.

The discharge coefficient $C$, as defined in [3] for incompressible single phase flow conditions, is Reynolds dependent. In multiphase flows, a Reynolds number Re was defined based on the liquid phase velocity and the full pipe diameter.

The expansibility factor, $\varepsilon$, is defined from the isentropic exponent of the gas phase, $k$, and the diameter ratio $\beta$ in order to account for the gas phase being compressible in multiphase flows, as described in $[3,4]$.

Therefore the parameter $C^{\prime}$ accounts for the phase slip velocity and the space distribution of the phases at the venturi throat. The Figure 7 presents plots of the multiplier $C^{\prime}$ versus the total mass flow rate, calculated from the test data obtained on both test-facilities.

In the second method, the pressure drop data obtained across the venturi have been compared with a two-phase flow model results. Such a model has been proposed in [5] and has been further discussed for the interpretation of twophase pressure drop across a venturi in [6].

In this model, the flow regime corresponds to a dispersed two-phase flow. The mass balances are written for the two phases and the momentum balance is expressed for the dispersed phase and for the mixture.

$$
\begin{gathered}
\frac{d}{d x}\left[A(1-\alpha) u_{L}\right]=0 \\
\frac{d}{d x}\left[A \alpha u_{p}\right]=0 \\
\rho_{p} u_{p} \frac{d u_{p}}{d x}+C_{m} \rho_{L}\left(u_{p} \frac{d u_{p}}{d x}-u_{L} \frac{d u_{L}}{d x}\right)+\frac{d P}{d x}+\tau_{D}=0 \\
\alpha \rho_{p} u_{p} \frac{d u_{p}}{d x}+(1-\alpha) \rho_{L} u_{L} \frac{d u_{L}}{d x} \\
=\frac{d P}{d x}-\rho_{L} g(1-\alpha)-\alpha \rho_{p} g-\tau_{W}
\end{gathered}
$$

where $u_{L}, u_{p}$ are the liquid and inclusions velocities, $\alpha$ is the gas fraction, $A$ is the varying cross-sectional area of the venturi, $C_{m}$ is the added mass coefficient (set at a value of $0.5), \tau_{D}$ is the drag force on the bubble, $P$ is the pressure and $\tau_{w}$ is the friction force at the wall.

The drag force is expressed as:

$$
\tau_{D}=-\frac{4 \Pi a^{3}}{3}\left|\rho_{L}-\rho_{p}\right| g \frac{\left(u_{p}-u_{L}\right)}{V_{t}} f\left(\frac{\left|u_{p}-u_{L}\right|}{V_{t}}\right)
$$

where $f \equiv 1$ when the liquid is pure and $f \equiv\left|u_{p}-u_{L}\right| / V_{t}$ when the bubble is in a contaminated liquid, $\rho_{p}$ is the inclusion density, a is the bubble radius and $V_{t}$ the bubble rise velocity in the quiet liquid.

This balance accounts for the added mass force, the pressure gradient force and a drag force. The added mass force accounts for the momentum flux of liquid phase entrained in the bubbles wake. In the case of flows through a venturi tube, this term can have a significant influence since there is a great acceleration through the throat. In this model, there are only four unknowns: the liquid mean velocity $u_{L}$, the bubble mean velocity $u_{p}$, the gas fraction $\alpha$ and the area averaged pressure $P$.

In the present work, the pressure drop calculations were performed with the homogeneous model. The main hypothesis consists in assuming no velocity slip between the two phases. There is only one velocity $u$ for the two phases. The system is then reduced to two equations, a first one for the total mass balance and a second one for the total momentum balance:

$$
\begin{gathered}
A \frac{d u}{d x}=-u \frac{d A}{d x} \\
{\left[(1-\alpha) \rho_{L}+\alpha \rho_{p}\right] u \frac{d u}{d x}=\frac{d P}{d x}+\tau_{W}+\left[(1-\alpha) \rho_{L}+\alpha \rho_{p}\right] g_{x}}
\end{gathered}
$$

For horizontal two-phase flows at high velocity, the velocity slip between phases at the venturi throat, predicted by the two-phase flow model, is shown to have a very small influence on the pressure drop between the venturi inlet and the venturi throat [7]. In this particular case, the homogeneous model gives results very close to those of the two-fluid flow model. It is then possible to use the homogeneous model to process the experimental data. The homogeneous model has been used by integrating the venturi geometry (variation of cross-section area $A$ along the axis) to predict the pressure drop between the inlet and throat of the venturi tested.

The Figures 8 and 9 present the plots of the ratio $100\left[\Delta P_{\text {measured }}-\Delta P_{\text {predicted }}\right] / \Delta P_{\text {measured }}$ calculated from the test data set obtained in both test-facilities.

\section{DISCUSSION}

A number in excess of 500 test results from the two testfacilities have been made available for the intercomparison 


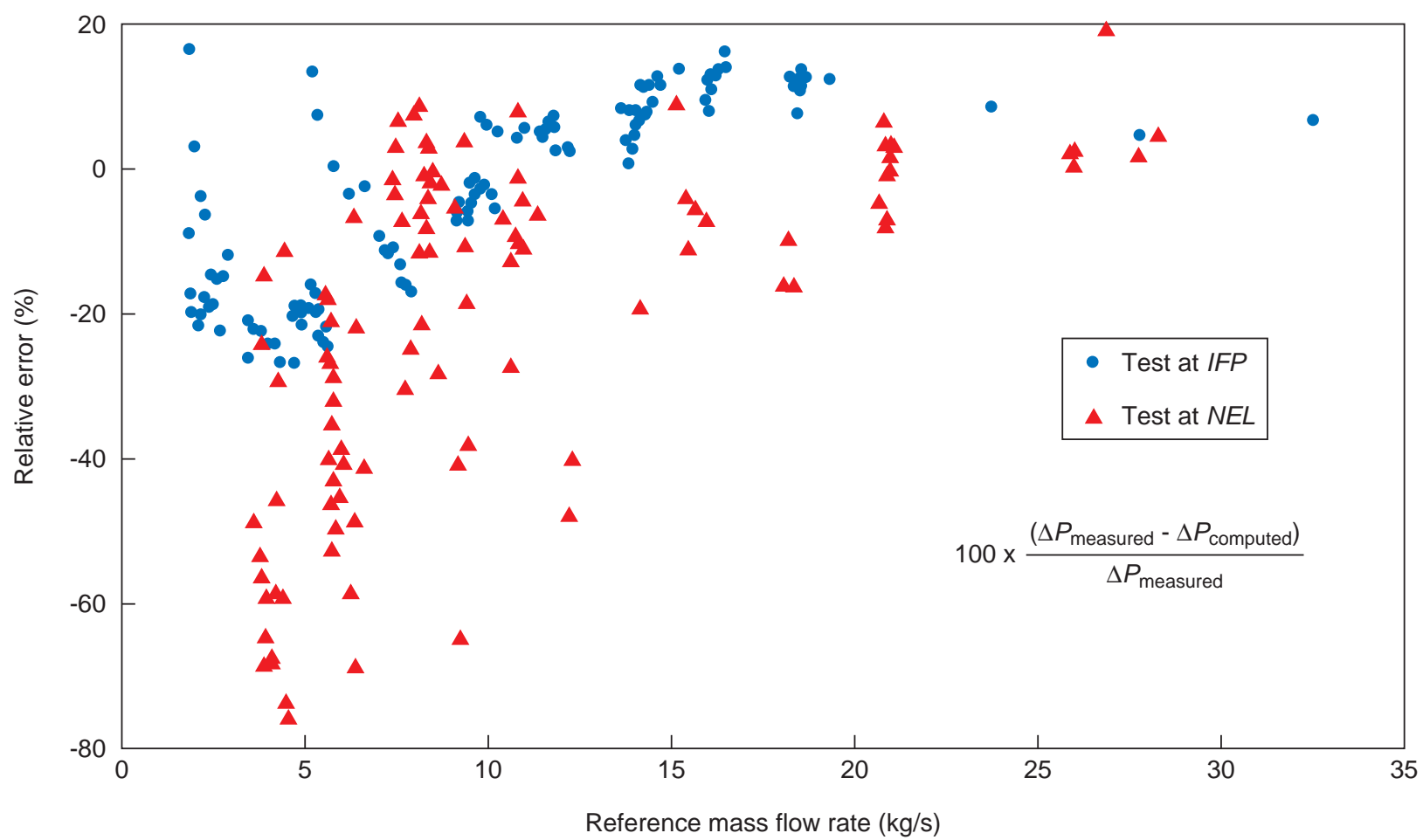

Figure 8

Relative differences between measured and computed pressure losses at the venturi throat versus total mass flow rate.

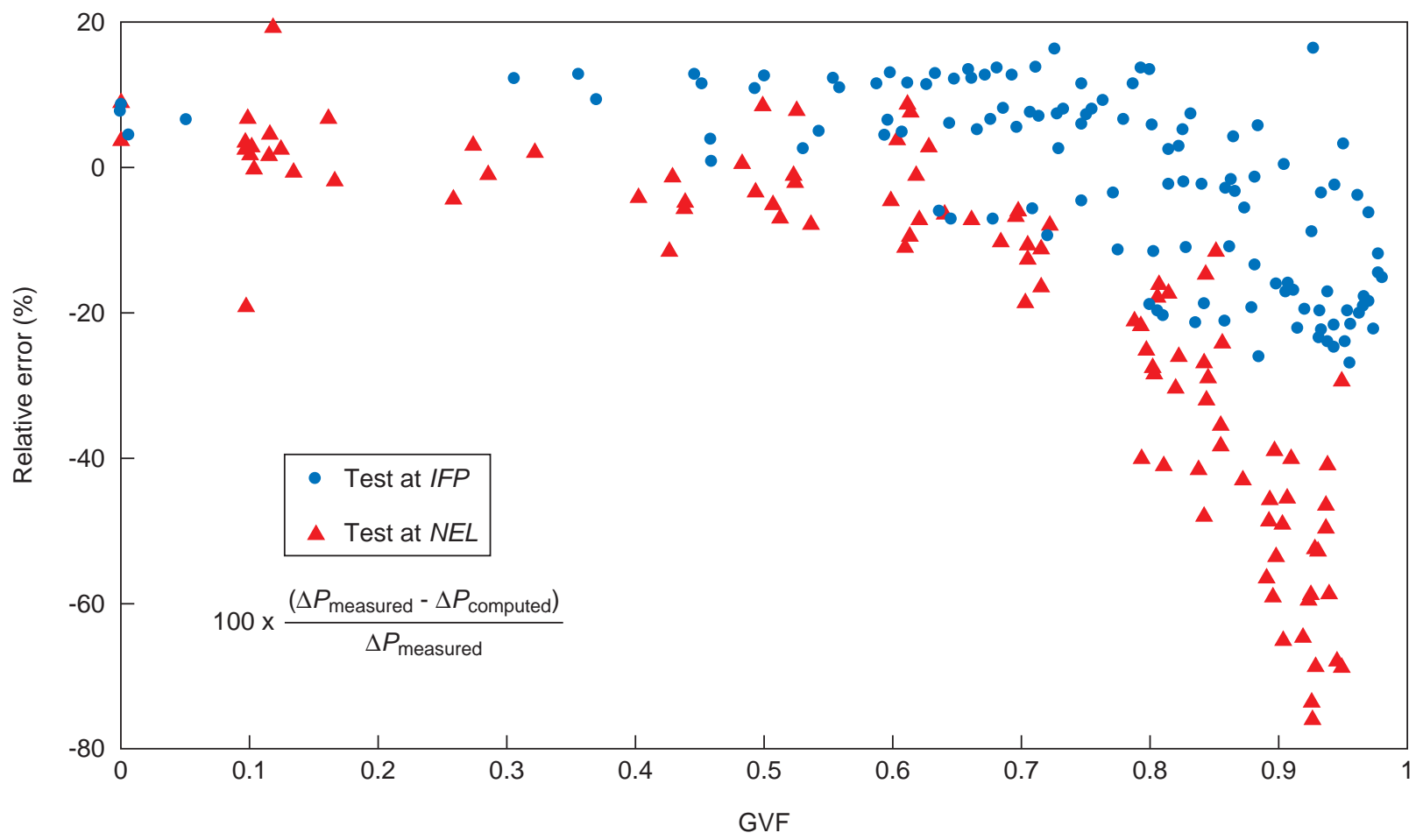

Figure 9

Relative differences between measured and computed pressure losses at the venturi throat over the range of gas fraction. 
study. These data cover the whole range of gas volume fraction and the experienced flow domains largely overlap. The test facility at $N E L$ offered a larger gas capacity at low static pressures but it is restricted to a maximum service pressure of $10^{6} \mathrm{~Pa}$. On the other hand, test data at several static pressures between $2 \times 10^{5}$ and $3 \times 10^{6} \mathrm{~Pa}$ at the venturi inlet could be recorded on the IFP test-loop.

The wide flow domain experienced enabled to perform the intercomparison study over a realistic range of flow conditions and allowed to check for the two effects of the Reynolds number and of the static pressure on the methods of data comparison evaluated in this study.

Test data were recorded for three and two phase flows of water, oil and nitrogen mixtures. However, because the slip velocity between the water and oil phases is assumed negligible in the experienced range of flows, testing with three phase flows was of secondary importance for the purpose of the intercomparison work. In addition, this assumption allowed to make use of a simple reference system and simplified methods of data analysis, as presented above.

Obviously, processing the data by means of the direct comparison of statistics derived from the raw signals would be a very limited approach in multiphase flows.

The computation of the venturi discharge coefficient $C^{\prime}$ gives a similar trend from data obtained at NEL and at IFP. All results lie within a $\pm 15 \%$ tolerance range around the average curve.

There is slightly more data scattering on $N E L$ data than on $I F P$ data. This could be due to the effect of greater flow instabilities during tests at $N E L$ as a result of the test fluids used and the lower operating pressure.

The effect of the static pressure is further seen by comparing the "IFP low pressure" and the "IFP high pressure" test results on Figure 7. The high pressure results are less scattered.

For the purpose of the intercomparison of multiphase flowmeters test facilities, the method based on the computation of a venturi pressure loss coefficient can be adopted. The limited data scattering observed around a mean correlation for the multiphase multiplier $C^{\prime}$ expressed as a function of the mass flow rate (Fig. 7), indicates that the venturi meter is suitable as a reference device.

The data comparison with the one-dimensional homogeneous flow model was made after a flow computation with a $1 \mathrm{~mm}$ mesh length.

Plotting the results versus the reference total mass flow rate puts in evidence an important data scattering (Fig. 8).

As shown on Figure 9, when plotted versus the gas volume fraction the predicted results lie within a $\pm 15 \%$ tolerance range around the experimental data recorded on both facilities, up to a gas content of $70 \%$ approximately. For gas volume fractions above $70 \%$, the model fails to predict the measured venturi pressure drops and the important data scattering was found independently of the static pressure of tests. The gas expansion, not taken into account in the model, cannot explain the data scattering because its effect is very limited on the tests at high static pressures. Rather, as confirmed by the visual observation of multiphase flows during testing, the poor performance of the model at gas volume fractions above $70 \%$ can be attributed to a change of flow patterns which enter the venturi. When slug, stratified or annular flows are formed, the slip velocity between phases can affect the measured venturi pressure loss to a large amount and causes the poor performance of the homogeneous flow model.

For a better accuracy in the higher range of gas volume fraction, the method could be refined by the use of a twofluid model. But, this would introduce the need for the additional information of the hydrodynamic regime of the flow which depends on the flow facility. This cannot be accepted in the framework of a general method of intercomparison because it must be dependent on the reference venturi system only.

\section{CONCLUSION}

An intercomparison study has been performed in order to gain a more detailed understanding of the multiphase flows generated from the calibration facilities at IFP and NEL. This effort is needed for the benefit of the multiphase meters manufacturers and users.

A simple venturi meter spool with a gamma densitometer can be used as a reference system for intercomparison and a method for data comparison can be defined. The method need to be intrinsic and accurate. The use of a multiphase flow model to relate the multiphase flow facility data and the signals measured on the reference system introduces additional uncertainty which will detract from the value of the comparison. For this reason, a method based on the computation of a venturi pressure loss coefficient is preferred.

\section{ACKNOWLEDGEMENTS}

The work performed at $N E L$ for this project was funded by the Flow Programme of the UK Departement of Trade \& Industry.

The authors are indebted to Dr. C. Boyer (IFP) and Dr. P. Pagnier $(I F P)$ for their great help and assistance during this work.

\section{REFERENCES}

1 Hall, A.R.W. and Reader-Harris, M.J. (1999) Use of Venturi Meters in Multiphase Flow Measurement. North Sea Flow Measurement Workshop, Oslo, 25-28 October 1999. 
2 Hall, A.R.W., Reader-Harris, M.J. and Millington, B.C.A. (2000) Study of the Performance of Venturi Meters in Multiphase Flow. 2nd Int. Multiphase Technology Conference, Banff, 21-23 June 2000.

3 Anonymous (1992) Section 1.1 Specification for SquareEdged Orifice Plates, Nozzles, and Venturi Tubes Inserted in Circular Cross-Section Conduits Running Full. In: British Standard BS 1042.

4 Atkinson, D.I., Bérard, M. and Ségéral, G. (2000) Qualification of a Nonintrusive Multiphase Flowmeter in Viscous Flows. Paper SPE 63118. Annual Tech. Conf. and Exhibition, Dallas, 1-4 October 2000.
5 Lewis, D.A. and Davidson, J.F. (1985) Pressure Drop for Bubbly Gas-Liquid Flow Through Orifice Plates and Nozzles. Chem. Eng. Res. Des., 63, 149-156.

6 Boyer, C. and Lemonnier, H. (1996) Design of a Two-Phase Metering Process for Two-Phase Dispersed Flows. Int. Journal of Multiphase Flow, 4, 713-732.

7 Boyer, C. and Lemonnier, H. (1996) Theoretical Modelling and Experimental Study of Three-Phase Dispersed Flows in a Venturi Tube. European Two-Phase Flow Group Meeting, Grenoble, June 1996.

Final manuscript received in October 2003 